\title{
Serviço Social, educação e racismo: uma articulação necessária
}

Social Work, education and racism: a necessary articulation Aline Batista de Paula*

\begin{abstract}
Resumo - O presente artigo resulta da primeira etapa de uma pesquisa de doutorado, cujo objetivo geral se constitui em refletir sobre o trabalho dos assistentes sociais nas políticas educacionais, e sua coadunação com as recentes legislações de combate ao racismo na área, que tiveram como lastro a Constituição Federal de 1988 e a Lei de Diretrizes e Bases da Educação - LDB (1996). Essa primeira fase trata-se de um mapeamento das produções dos programas de pós-graduação em serviço social sobre racismo na educação, na base de dados da Coordenação de Aperfeiçoamento de Pessoal de Nível Superior - CAPES. Considera-se no texto a importância da Educação, e das políticas educacionais, enquanto instrumentos no combate ao racismo e a discriminação racial no Brasil buscando apreciar a relação dialética destas políticas com a sociedade, assim como sua dimensão política no interior dos processos de socialização.
\end{abstract}

Palavras-chave: Serviço Social; educação; racismo; políticas educacionais.

\begin{abstract}
This article is the result of the first stage of a doctoral research, whose general objective is to reflect on the work of social workers in educational policies and their alignment with recent legislation to fight racism in the field, based on the Brazilian Federal Constitution of 1988 and the Law of Guidelines and Bases for Education (1996). The first phase consists of mapping the output of postgraduate programs in social work about racism in education, available on the database of the Coordination of Improvement of Higher Education Personnel (Capes, in Portuguese). The importance of education and of educational policies as instruments to fight racism and racial discrimination in Brazil is taken into account, while seeking to appreciate the dialectic relationship of these policies with society, as well as its political dimension within the processes of socialization.
\end{abstract}

Keywords: social work; education; racismo; educational policies.

\footnotetext{
* Assistente social. Doutoranda do Programa de Pós-graduação em Serviço Social da UERJ, bolsista da FAPERJ. E-mail: alinebpaula81@gmail.com. ORCID: https://orcid.org/0000-0003-3399-6687.
} 


\section{ReVIStg a d P p putt}

\} SERVIÇO SOCIAL, EDUCAÇÃO E RACISMO - PAULA, A. B.

DOI: $10.12957 /$ REP.2020.47223

\section{Introdução}

O presente artigo é resultado de uma fase inicial de uma pesquisa de doutorado cujo objetivo geral se constitui em refletir sobre o trabalho dos assistentes sociais nas políticas educacionais, bem como sua coadunação com as recentes legislações de combate ao racismo na área, que tiveram como lastro a Constituição Federal de 1988 e a Lei de Diretrizes e Bases da Educação (LDB - 1996). Essa primeira fase trata-se de um mapeamento das produções dos programas de pós-graduação em Serviço Social sobre racismo na educação.

Nesse sentido, o âmago da reflexão se ancora nas transformações ocorridas principalmente nas décadas de 1970, 1980 e 1990, de forma concomitante: no interior da profissão - pelo processo de renovação e sua consequente mudança de direção teórica e social. Essas mudanças estavam no bojo do Movimento de Reconceituação do Serviço Social latino-americano (1965-1975) e nas políticas públicas decorrentes do processo de redemocratização do país, especialmente pela intensa mobilização dos movimentos sociais, de diversos segmentos, em prol de direitos sociais, políticos e civis; dentre essas políticas, ade educação.

As lutas encampadas pelos mais diversos movimentos sociais adquiriram uma legitimidade e força políticas que barraram provisoriamente as orientações internacionais de reforma neoliberal do Estado. Cabe ressaltar que desde o fim dos anos 1970, ampliado pela crise mundial do petróleo, ocorria o que Mandel (1982) denominou de o fim da onda longa de expansão capitalista (1945-1973). Nesse períodose instauraram as bases para a crise estrutural do capital (MÉSZÁROS,2011), da qual decorreram medidas de ajustes para a restauração das taxas de lucro, em diversos países no mundo, mas que no Brasil foram refreadas pelo processo de redemocratização.

Em grande parte como consequência destas mobilizações, especificamente na política de educação, tanto na Constituição de 1988, como na LDB, buscou-se incorporar vieses mais inclusivos e democráticos, na tentativa de respeitar a diversidade e a complexidade da população brasileira. Os princípios fundamentais da educação enquanto direito de todos, junto à necessidade de criação de igualdade de condições para acesso e permanência na escola, demarcados por essas legislações, criam uma gama de novas possibilidades no que se refere tanto aos processos educacionais, quanto às demandas de novos profissionais, como o assistente social.

Também nesse momento, se reconstroem as bases teórico-metodológicas e ético-políticas do reconhecimento do Serviço Social. Com base na tradição marxista, esta passa a ser explicada enquanto uma profissão cuja dinâmica se constrói nos marcos do capitalismo. O Projeto Ético-Político profissional, elaborado nesse processo de transformação e materializado tanto nos marcos legais - a lei de regulamentação da profissão, em 1993, e o Código de Ética de 1993 - quanto nas produções intelectuais fundamen- 


\section{ReVIStG PMI PDUtD}

\} SERVIÇO SOCIAL, EDUCAÇÃO E RACISMO - PAULA, A. B. \}

DOI: $10.12957 /$ REP.2020.47223

tadas no referencial marxista, demarcou para a profissão a necessidade de articulação entre a percepção crítica da realidade e a reflexão teórica da prática profissional.

Porém, apesar das profundas transformações sofridas pela profissão na tentativa de superação do seu caráter conservador nas últimas três décadas, no que se refere ao debate racial dentro do Serviço Social, ainda há muita resistência dos profissionais em aprofundar o debate no sentido de compreensão do racismo como estrutural e estruturante das relações sociais.

A própria escolha da categoria profissional pela inserção, nos princípios fundamentais do Código de Etica de 1993, do termo "etnia", ao invés de "raça", pode ser considerada um bom indicador de que essa reflexão se coloca como fundamental. O debate sobre raça, racismo e discriminação racial se baseia na construção de um sistema hierárquico de classificação de pessoas, o qual foi utilizado como forma de exploração e escravização através do globo. Etnia, por sua vez, trata-se deum conjunto sociocultural, histórico e psicológico, que segundo Munanga (2003) se constitui em uma categoria lexical mais aceitável que raça.

Em termos de políticas públicas, e ainda que existam críticas pertinentes ao formato do enfrentamento ao racismo no Brasil, também é fato que ocorreu a institucionalização de diversas das demandas históricas dos movimentos negros por parte do Estado. De acordo com Paula (2017), a partir da eleição do Presidente Lula (2003) e ao longo dos seus mandatos (2003-2011), as questões relativas à igualdade racial ocuparam algum espaço na agenda pública nacional ${ }^{1}$, especialmente com a criação da Secretaria Especial de Promoção da Igualdade Racial (Seppir) em 2003.

A Seppir foi responsável pela transversalização do debate racial com as outras políticas públicas setoriais, alicerçando, assim, as demais legislações promulgadas subsequentemente, como: a Lei $n^{\circ} 10.639 / 2003$, que institui, na rede básica de ensino, o ensino obrigatório de história e cultura afro-brasileira e africana; a Lei ${ }^{\circ} 11.645 / 2008$,que inclui no currículo a obrigatoriedade do estudo da história e cultura dos povos indígenas; o Programa de Combate ao Racismo Institucional (2005); a Política Nacional de Saúde Integral da População Negra (2009); e o Estatuto da Igualdade Racial (2010), dentre outras.

Diante do exposto, o debate posto neste artigo ressalta a exigência por assistentes sociais compromissados com a luta antirracista, mais especificamente os que atuam na política de educação, que se percebam como parte ativa da dinâmica social e das demandas postas pelos movimentos sociais, instituídos como direitos pelas legislações, como expressões particulares da luta de classes no país.

\footnotetext{
1 Fruto de uma intensa mobilização dos movimentos negros brasileiros nas décadas anteriores e da Conferência Mundial Contra Racismo, Discriminação Racial, Xenofobia, Discriminações Correlatas, que ocorreu em Durban no ano de 2001, organizada pela ONU, assim como todo o seu processo preparatório, que foram cruciais para colocar o racismo e seu enfretamento em pauta.
} 


\section{ReVIStg am P puttg}

\} SERVIÇO SOCIAL, EDUCAÇÃO E RACISMO - PAULA, A. B. \}

DOI: $10.12957 /$ REP.2020.47223

Dessa forma, busca-se na primeira parte do texto fazer uma reflexão conceitual da ontologia do trabalho, com base na teoria marxista, articulandoo com a construção da cultura e estabelecendo a relação entre cultura e racismo como fundamento para expansão capitalista e exploração de classe. Pretende-se, através desse debate, trazer fundamentos consistentes para demonstrar a relevância dessa reflexão na categoria profissional, e mais especificamente nesse artigo, para o trabalho dos assistentes sociais na área de educação.

Destarte, considerando a importância do debate racial para atuação dos assistentes sociais, na segunda parte do texto fez-se um estado da arte na base de dados da Coordenação de Aperfeiçoamento de Pessoal de Nível Superior (Capes), mapeando teses e dissertações na área de concentração do Serviço Social que articulem o debate entre educação, racismo e Serviço Social. Esse tipo de pesquisa, conforme ressalta Ferreira (2002), é reconhecido pela sua metodologia de caráter inventariante e descritivo da produção acadêmica e científica, buscando investigar, à luz de referidas categorias, como se caracterizam enquanto tais em cada trabalho e no conjunto deles. Isto posto, partindo do pressuposto fundamental da relação indissociável entre teoria e prática, pretende-se refletir como a categoria profissional vem ou não se debruçando sobre essa discussão.

\section{Considerações basilares para compreensão do trabalho do assistente social na educação e sua relação com o racismo}

Na tradição marxiana que embasa hegemonicamente o trabalho dos assistentes sociais desde a sua renovação, o fundamento ontológico do trabalho se situa na capacidade humana de transformar a natureza para suprir as suas necessidades de existência. Essa ação, contudo, depende da capacidade teleológica do ser humano, que de forma mais simples é sua capacidade de elaborar e aprender.

O trabalho se alicerça na aptidão humana de dar fim consciente às suas ações, por intermédio da compreensão da dinâmica do espaço onde vive, do conhecimento das propriedades e dos elementos da natureza. A ideação do sujeito antes de efetivar a atividade do trabalho, assim como o espelhamento do seu resultado, está ancorada em um conhecimento préestabelecido. Conforme novos aprendizados são agregados, o conhecimento humano se torna mais complexo, pois, à medida que se reproduzem técnicas usadas por outros seres humanos, ou ainda ao se produzirem novas técnicas, a ação humana se torna um motor imensurável de ideias.

Como criador de valores de uso, como trabalho útil, o trabalho é, assim, uma condição de existência do homem, independente de todas as formas sociais, eterna necessidade natural de mediação do metabolismo entre homem e natureza e, portanto, da vida humana. (MARX, 2012, p. 167). 


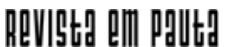

\} SERVIÇO SOCIAL, EDUCAÇÃO E RACISMO - PAULA, A. B. \}

DOI: $10.12957 /$ REP.2020.47223

A complexificação do conhecimento impele aos sujeitos o desprendimento das experiências empíricas imediatas, estimulando-os a compartilhar seus saberes. Nesse sentido, a condição para o aprendizado demanda a construção de certo tipo de linguagem articulada, que alicerça tanto a sua comunicação, quanto o seu processo de aprendizagem. De acordo com Aranha (1990), as relações, seja entre os homens ou com a natureza, são intermediadas por símbolos ou sistema de representações aceitas pelo grupo, tornando-se meios pelos quais os homens representam o mundo.

O valor converte, antes, todo produto do trabalho num hieróglifo social. Mais tarde, os homens tentam decifrar o sentido desse hieróglifo, desvelar o segredo de seu próprio produto social, pois a determinação dos objetos de uso como valores é seu produto social tanto quanto a linguagem. (MARX, 2012, p.209).

Os hieróglifos sociais apontados por Marx na verdade se constituem enquanto um conjunto de símbolos que serão elaborados em determinado tempo e lugar. Esse sistema de representações é o que chamamos de cultura. Aranha (1990, p.14) ressalta que "cultura é o resultado de tudo aquilo que o homem faz para produzir a sua existência", e nesse sentido consegue exprimir as várias formas pelas quais os seres humanos estabelecem suas relações, seja com outro homem ou com a natureza. Nessa acepção, a condição humana é resultante da assimilação de modelos sociais, ou seja, o estar em sociedade é mediado pela cultura.

A autora aponta outra importante questão quando afirma que o "mundo cultural é um sistema de significados pré-estabelecido por outros" (ARANHA, 1990, p.16). Essa afirmação abre brecha para duas colocações extremamente relevantes. A primeira é que todo o conhecimento é um conhecimento acumulado, e nesse sentido pode-se dizer que ele não é estanque no tempo e no espaço. A segunda colocação nos faz pensar que esse sistema é capaz de não somente produzir, mas também de perpetuar hierarquias e "verdades universais".

Fanon (1980) coloca que é necessário prestar atenção a uma visão unilateral da cultura. "Em primeiro lugar afirma-se a existência de grupos humanos sem cultura; depois, a existência de culturas hierarquizadas; por fim, a noção de relatividade cultural" (FANON, 1980, p.35). Ainda de acordo com o autor, o desenvolvimento técnico e elevado de determinado grupo social autoriza-o a instalar uma dominação organizada. Nesse sentido, "O empreendimento da desculturação apresenta-se como o negativo de um trabalho mais gigantesco, de escravização econômica e mesmo biológica" (FANON, 1980, p.36).

A expansão capitalista moderna, com base no que Quijano (2005) chama de coloneidade, fundou-se através da convergência e associação de dois processos históricos: a codificação das diferenças a partir de uma concepção de raça, que situou os conquistados em uma relação de inferioridade 


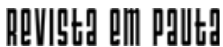

\} SERVIÇO SOCIAL, EDUCAÇÃO E RACISMO - PAULA, A. B. \}

DOI: $10.12957 /$ REP.2020.47223

com os conquistadores, sendo o elemento essencial nas relações de dominação; e a articulação e controle de todas as formas de trabalho em prol do capital e do mercado mundial.

Munanga (2003) aponta que, como a maioria dos conceitos, o de raça tem seu campo semântico e uma dimensão no tempo e no espaço. Inicialmente pertencente às ciências biológicas, ele foi, principalmente a partir do século XVII, utilizado para justificar relações de dominação e de sujeição. Anteriormente, a noção do "outro" tinha base na teologia, tendo a Igreja Católica o monopólio da razão; entretanto, com o avanço dos ideais iluministas buscou-se uma "cientificidade" para explicação da diversidade humana, e assim construir outra forma de legitimação para a hierarquização e escravização.

É importante ressaltar, segundo Fanon (1980), que racismo e cultura possuem uma reciprocidade. Se a cultura se forja no conjunto dos comportamentos motores e mentais da relação do homem com a natureza e com o seu semelhante, devemos dizer que o racismo é sem sombra de dúvida um elemento cultural. Todavia, a sua forma de percepção e de utilização não se mantém estanque. Ele se transformou para atender às necessidades de exploração da sociedade, principalmente a capitalista.

A ideia de raça, conforme ressalta Quijano (2005), produziu novas identidades históricas e essas foram associadas a novos papéis nessa nova estrutura global de controle de trabalho. Nesse sentido, o autor coloca que raça e divisão de trabalho foram associadas de forma estrutural, se reforçando mutuamente, mesmo que não dependam um do outro para existir ou para se transformar.

Dada a sua relevância no desenvolvimento humano e social, o processo educativo (formal ou informal) sempre foi alvo de disputa na sociedade capitalista. Almeida (2005) observa que a educação se constitui enquanto uma dimensão complexa e histórica da vida social; destarte, a política educacional é compreendida enquanto expressão das lutas de classes, sendo também responsável pela formação de consensos e reprodução da força de trabalho.

Pode-se dizer, então, que é necessário educar para o trabalho na lógica do capitalismo, especialmente no que se refere às transformações tecnológicas para o desenvolvimento da produção. Mas, sobretudo, é necessário educar para os valores capitalistas da individualidade, da concorrência, da importância do trabalho árduo para uma fictícia possível ascensão de classe social, como também para a manutenção do racismo, que opera dentro da racionalidade capitalista.

Um ponto interessante a ser destacado é que, desde o fim do século XIX no Brasil, constrói-se um projeto higienista de Estado, que, baseado na miscigenação, procurava o desenvolvimento da nação através do embranquecimento. Esse processo culminou no que vários teóricos denominaram de democracia racial. A democracia racial, que posteriormente constatou- 


\section{ReVIStG PMI PDUtD}

\} SERVIÇO SOCIAL, EDUCAÇÃO E RACISMO - PAULA, A. B. \}

DOI: $10.12957 /$ REP.2020.47223

se ser um mito, refutava o determinismo biológico ao enfatizar o amálgama cultural e harmônico entre as raças que compunham o país. Contudo, esse mito serviu por várias décadas como um eficaz instrumento de dominação, tornando-se determinante para o acirramento das desigualdades raciais. Dessa maneira, foi usado como justificativa para a omissão do Estado na formulação de políticas públicas destinadas à superação das desigualdades raciais no país.

Como então os assistentes sociais vão se inserir nesse cenário? O Serviço Social, desde a sua renovação, é entendido no quadro das relações sociais entre as classes sociais e destas com o Estado. A partir da compreensão crítica da profissão, o trabalho do assistente social foi interpretado como processo no interior de processos mais amplos, que se transforma ao modificarem-se as condições e as relações sociais nas quais está circunscrito. Uma profissão configurada dentro da divisão social e técnica do trabalho, relacionada, portanto, ao modo de produção capitalista. Opera na produção e reprodução das relações sociais, atuando nas contradições de classe e tendo sua materialidade constituída no enfrentamento às expressões da questão social, gerada pelas sequelas da exploração da força de trabalho pelo capital.

Logo, as demandas pela atuação dos assistentes sociais nas políticas educacionais serão aquelas relacionadas às necessidades do capital operante. Nas últimas décadas, esse espaço sócio-ocupacional vem crescendo consideravelmente. Pode-se atribuir esse crescimento, primeiramente, às transformações no campo das políticas educacionais - em especial pelas lutas dos movimentos sociais na década de 1980 -,que começaram a ter uma maior compreensão do peso dos determinantes sociais, culturais, históricos e econômicos na vida dos alunos, dos educadores e consequentemente no espaço educacional. Então, as condições de vida e as relações estabelecidas por esses sujeitos conformam particularidades que impactam no processo ensino-aprendizagem, criando a demanda por profissionais que possam fazer essas mediações.

Um segundo aspecto a ser considerado são as transformações no campo das políticas sociais, após a promulgação da Constituição de 1988. Nesse sentido, é importante ponderar a incorporação da política de assistência social como integrante do tripé da Seguridade Social, que, através dos seus programas de transferência de renda, especialmente o Bolsa Família, exigiu uma maior articulação com outras políticas setoriais no atendimento das suas condicionalidades, que no caso da política educacional foi da frequência escolar. Essa nova requisição passou a demandar à comunidade escolar um novo tratamento a respeito da evasão.

Deve-se evidenciar também, de acordo com Almeida (2003, p. 2), que a presença dos profissionais de Serviço Social no campo da política educacional necessita ser observada como "uma reflexão de natureza política e profissional sobre a função social da profissão em relação às estratégias de 


\section{Revistg am p puttg}

\} SERVIÇO SOCIAL, EDUCAÇÃO E RACISMO - PAULA, A. B. \}

DOI: $10.12957 /$ REP.2020.47223

luta pela conquista da cidadania através da defesa dos direitos sociais das políticas sociais". Pondera-se, nessa acepção, que esses novos espaços sócioocupacionais dos assistentes sociais são respostas tanto das dinâmicas sociais, quanto das transformações na profissão, através da construção e consolidação do Projeto Ético-Político profissional, assimilando sua função social e luta pela defesa e ampliação dos direitos e das políticas sociais.

A dimensão ético-política da profissão, articulada às dimensões teórico-metodológica e técnico-operativa, contribui para a consolidação do seu papel enquanto trabalhador social, assim como seus métodos de ação. Ao fazer a opção política por uma reflexão crítica que desvele a realidade tanto do fazer profissional, quanto dos usuários dos serviços, o assistente social assume o trabalho de contribuir no fortalecimento da percepção daqueles enquanto sujeitos de direitos, para que compreendam como são influenciados pela ideologia dominante.

Certamente, apenas a percepção do condicionamento da estrutura no cotidiano não garante por si só a transformação social, contudo, esses usuários/sujeitos têm a possibilidade de conseguir se relacionar também de forma crítica, demandando assim o acesso mais amplo e qualitativo dos seus direitos. Freire (1981, p.53) ressalta que a "consciência de e ação sobre a realidade são inseparáveis constituintes do ato transformador pelo qual homens e mulheres se fazem seres de relação". Essa reflexão é reforçada por Abreu (2002), ao observar que a dimensão pedagógica do assistente social se determina com os vínculos que estabelece com cada classe social, sendo materializada na forma como a atuação profissional incide sobre o pensar e o agir daqueles sob os quais a sua prática incide.

A partir do exposto, pode-se verificar que a opção política dos profissionais articula o projeto profissional ao projeto societário, pois toda a prática em uma sociedade classista tem caráter político. Todo o trabalho profissional do assistente social é perpassado por interesses políticos, sociais e ideológicos que estão postos na sociedade. Dessa forma, qualquer prática terá em si uma determinada direção social, que se refletirá em valores e diretrizes profissionais (TEIXEIRA; BRAZ, 2009; NETTO,1999).

\section{Serviço Social, educação e racismo: mapeamento da produção teórica da profissão}

A pesquisa aqui apresentada focou-se exclusivamente no campo educacional, buscando fazer um mapeamento da produção acadêmica, de caráter exploratório, denominada no campo científico de "Estado da Arte" ou "Estado do Conhecimento" (FERREIRA, 2002) sobre a articulação entre Serviço Social, educação e racismo. O objeto do estudo foram teses e dissertações publicadas no banco de dados da Capes no período de 2005, onde é registrada a primeira dissertação sobre o tema até o ano de 2018. 


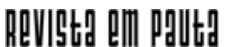

\} SERVIÇO SOCIAL, EDUCAÇÃO E RACISMO - PAULA, A. B. \}

DOI: $10.12957 /$ REP.2020.47223

Os filtros utilizados na pesquisa foram: grande área de conhecimento das ciências sociais aplicadas; área de conhecimento Serviço Social. Ademais, foram usadas as seguintes palavras-chave: Serviço Social, educação e racismo, todas entre aspas e com o conectivo and, para que os termos fossem pesquisados conjuntamente.

Constatou-se que foi defendido um total de 14 trabalhos, sendo nove teses de doutorado e cinco dissertações de mestrado, de cinco universidades públicas (UFPE - 1; UFF -3; UFRJ - 2; UFMA - 1; e UFC - 1) e cinco universidades particulares (Univ. Cat. de Pelotas - 1; PUC-RJ - 2; PUCSP - 1; PUC-RS - 1; e Esc. Sup. da Santa Casa de Misericórdia de Vitória - 1). Com relação às temáticas trabalhadas, dividiam-se das seguintes maneiras:

a) Ações afirmativas (cotas raciais) - foram um total de seis trabaIhos, sendo três dissertações e três teses;

b) Lei ${ }^{\circ} 10.639 / 03$ (educação para as relações étnico-raciais) - foram cinco trabalhos: duas dissertações de mestrado e três teses de doutorado;

c) Política de promoção de igualdade racial- uma tese de doutorado;

d) Formação profissional do assistente social - uma tese de doutorado;

e) Educação popular (gênero e racismo) - uma tese de doutorado.

Pode-se constatar que os temas estão intrinsicamente relacionados com as políticas educacionais antirracistas que se efetivaram nos anos 2000: sejam as políticas de ações afirmativas, de caráter redistributivo e reparatório, que visam combater os efeitos acumulados da discriminação e exclusão social através do acesso às políticas sociais, como as cotas raciais nas universidades públicas; sejam, ainda, as políticas de ações valorativas, como as decorrentes das leis $\mathrm{n}^{\circ} 10.639 / 03$ e $\mathrm{n}^{\circ} 11.645 / 08$ (que conjuntamente instituem o ensino na rede básica de história e cultura africana, afro-brasileira e indígena), de caráter universal. Essas leis, segundo Paula (2011),têm como objetivo a ressignificação de valores e conceitos, buscando desconstruir mecanismos ideológicos que dão sustentabilidade aos mitos da inferioridade do negro e do índio, bem como da democracia racial. Conforme ressalta Munanga (1996), "significam um esforço deliberado, não apenas para interditar as manifestações de racismo, mas também para reduzir o seu impacto" (MUNANGA, 1996, p.90).

As ações valorativas espraiaram-se através de todos os níveis de ensino - infantil, básico, superior - e repercutiram para além dos conteúdos ministradosnas salas de aula da rede básica de ensino. Para a implementação dessas legislações, requereu-se um processo de formação que abrangesse os demais educadores, não somente os professores. Além disso, conforme ressaltado nas Diretrizes Curriculares para o Ensino das Relações Raciais, elaboradas pelo Ministério da Educação(2004), dependem de trabalho conjunto, de articulação entre processos educativos escolares, de políticas 


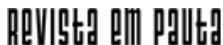

\} SERVIÇO SOCIAL, EDUCAÇÃO E RACISMO - PAULA, A. B. \}

DOI: $10.12957 /$ REP.2020.47223

públicas e de movimentos sociais, visto que as mudanças éticas, culturais, pedagógicas e políticas nas relações étnico-raciais não se limitam à escola.

Ao analisar os dados, consegue-se notar que os programas de pósgraduação em Serviço Social estão, nos últimos anos, se aproximando dos estudos sobre a educação para as relações étnico-raciais. Porém, com exceção de uma tese que pesquisa a formação profissional - apropriação da reflexão das relações raciais nos currículos dos cursos de Serviço Social -, os trabalhos tendem a debater apenas as políticas educacionais de combate ao racismo. Não foi encontrada nenhuma tese ou dissertação que refletisse sobre como os assistentes sociais que atuam na política de educação articulam esses debates.

Isso não significa propriamente um demérito, levando-se em consideração o crescimento do debate ao longo das duas últimas décadas e a redução do espaçamento entre as produções - 2005(1), 2010 (1), 2011(1), 2012(1), 2013(3), 2014 (1), 2015(1), 2016 (2), 2017 (2), 2018 (1). Todavia, compreende-se que há a necessidade de um maior esforço teórico-científico para a ampliação significativa dessa discussão, que ainda está muito obliterada.

É importante salientar que a ação educativa tem dimensão política dentro do processo de socialização. Dependendo do seu direcionamento, pode criar uma contracultura ou reafirmar as bases hierárquicas que mantêm as desigualdades sociais. Dessa forma, a educação em sua relação dialética com a sociedade é ao mesmo tempo razão e produto de transformação social.

A constituição de uma educação emancipadora passa pela capacidade de compreensão das estruturas sociais que potencializam o processo de exploração do capital sobre a força de trabalho. Logo, a análise da política educacional, na sua relação com a produção e a reprodução do capitalismo, tangencia o entendimento de que a conformação do capitalismo na modernidade está diretamente relacionada ao racismo.

A Escravidão no Brasil durou quase quatro séculos, fazendo com que o racismo se amalgamasse às estruturas sociais, tornando-se um eficaz instrumento de hierarquização/dominação. Se inicialmente o racismo colocou os negros no lugar do trabalho escravizado, ao longo dos séculos subsequentes ele se moldou para que eles fossem mantidos em situações subalternas e precarizadas de trabalho, considerando a inferioridade que lhes foi atribuída.

O Estado brasileiro, tanto na abolição formal da escravatura (1888), quanto no início da democracia republicana (1889), não desenvolveu nenhum tipo de política que pudesse atender aos ex-escravizados². Segundo

\footnotetext{
${ }^{2}$ Nesse texto usaremos o termo escravizado ao invés de escravo por compreender que se trata de uma condição, e não a essência do ser humano. Contudo, nas citações manteremos o termo original usado pelos autores, respeitando assim o contexto sócio-histórico de desenvolvimento do pensamento do autor.
} 


\section{ReVIIStR PM PDUtD}

\} SERVIÇO SOCIAL, EDUCAÇÃO E RACISMO - PAULA, A. B. \}

DOI: $10.12957 /$ REP.2020.47223

Paula (2011), a expansão republicana e a ênfase na igualdade e cidadania, que são facilmente associadas às repúblicas, não estavam relacionadas aos negros, que eram considerados cidadãos de segunda classe. Na verdade, os ideais democráticos e a ideologia racial (característica de uma sociedade fundamentalmente hierárquica) caminharam juntos na construção da nação brasileira.

Por ser o ex-escravo considerado excedente no novo campo de oportunidades que se abria, não houve nenhuma política de readaptação, integração ou assimilação dele ao sistema que se criava. Quando surgiu o trabalho assalariado no Brasil, como forma de produção, o ex-escravo, que até antes da abolição se encontrava no seu centro, recebeu imediatamente, o impacto oriundo de outra corrente populacional que vinha para o Brasil vender a sua força de trabalho: o imigrante. Esse fluxo migratório, ao entrar no mercado de trabalho deslocava o ex-escravo do centro do sistema de produção para a sua periferia, criando as premissas econômicas da sua marginalização. (MOURA, 1977, apud SILVA, 2017, p. 26).

As desigualdades sociais, condensadas na questão social, são vividas por um contingente majoritário de trabalhadores, desprovidos da propriedade dos meios de produção, mas providos de condições específicas e diferenciadas de raça, classe e gênero. Por conseguinte, conforme aponta Silva (2017), as classes sociais não são definidas apenas pelas posições que os sujeitos ocupam na sociedade, do ponto de vista das relações de trabalho, mas também pelas relações culturais, o conjunto de ideias e valores que organizam e dão sentido às determinações concretas da realidade.

Logo, o enfrentamento das múltiplas expressões da questão social, objeto principal do trabalho dos assistentes sociais, não pode prescindir da apreensão crítica das relações étnico-raciais na formação social e histórica brasileira. Da mesma forma, deve-se compreender o papel exercido pelos movimentos negros através de suas reivindicações contra o racismo, apontando-o enquanto uma questão política nacional e pressionando em prol de políticas estatais de combate ao racismo e à discriminação racial.

Silva (2017b) ressalta que o domínio teórico-metodológico e o referencial ético-político somente poderão ter sentido para as necessidades cotidianas da vida quando relacionados às propostas de ações nos marcos das demandas e lutas dos sujeitos coletivos e dos grupos sociais por seus direitos. A autora ainda aponta que as apreensões críticas dos processos sociais em sua totalidade, vinculadas à análise do movimento histórico da sociedade brasileira, são estratégicas para pensar as particularidades do desenvolvimento do capitalismo brasileiro.

Como fenômeno concreto da realidade contemporânea, verificase através dos dados da Pesquisa Nacional por Amostra de Domicílios (PNAD, 2015) que os negros (53,92\% do total nacional) representam o percentual populacional referente aos mais empobrecidos (entre os $10 \%$ mais pobres, 


\section{Revistg am p puttg}

\} SERVIÇO SOCIAL, EDUCAÇÃO E RACISMO - PAULA, A. B. \}

DOI: $10.12957 /$ REP.2020.47223

$25,4 \%$ são brancos e $74,2 \%$ são negros). Todavia, mais do que afirmar que os negros estão nos extratos mais baixos da população, o debate aqui traçado busca refletir o porquê de eles ainda se manterem, depois de tantos séculos, nessa condição. Dessa forma, é necessário atentar para o fato de que se construiu um sistema baseado em hierarquia racial que configurou as relações sociais em relação de dominação.

As identidades construídas e atribuídas nesse processo-branco, negro, índio, mestiço, mulato etc. -, de acordo com Quijano (2005), foram associadas a lugares e papéis sociais correspondentes a um padrão hierárquico, perpetuado de forma contínua dentro da sociedade, ou seja, trabalhadores "descartáveis". Nesse contexto, estabeleceu-se um padrão cultural universal que é europeu; logo, as ricas, diversas e heterogêneas culturas foram homogeneizadas e sobrepujadas.

A Europa concentrou a hegemonia da cultura e da produção do conhecimento com intuito de estabelecer formas de controle do trabalho que estivessem em consonância com a expansão do capitalismo em esfera global. Partindo dessa acepção, há o que Gonzalez (1988, p. 71) chama de um branqueamento cultural e linguístico, baseado em uma "ciência da superioridade branca cristã", que produziu um processo de alienação e fez com que a dominação e a violência coloniais fossem travestidas de verdadeira superioridade.

Isto posto, o estudo das relações raciais seria um pressuposto para a compreensão do desenvolvimento das forças produtivas, no processo de produção e reprodução da sociedade capitalista, considerando as diferentes esferas que fazem parte dele, em sua relação dialética e histórica. Contudo, a categoria profissional, ao longo das últimas décadas, consideradas como o fim do seu processo de renovação, tem sido muito resistente em incorporar o debate racial dentro da sua reflexão sobre trabalho - eixo central da teoria do valor de base marxiana.

Diversos estudos vêm debatendo essa lacuna dentro do Serviço Social, dentre os mais expressivos citamos: Rocha (2014), Rocha (2009), Marques Júnior (2007),Silva Filho (2006), Amaro (2005),Pinto (2003) e Ribeiro (2004). De forma geral, essas produções mapearam os trabalhos apresentados no Congresso Brasileiro de Assistentes Sociais (CBAS), em artigos na Revista Serviço Social e Sociedade (a mais expressiva da categoria), em teses, dissertações e nos currículos do curso de Serviço Social.

Diante do exposto, pode-se constatar que, apesar de haver um crescimento significativo das produções nas últimas duas décadas, inclusive com publicações de alguns dossiês temáticos em revistas importantes para a profissão, bem como com inclusão de algumas disciplinas na grade curricular, o debate sobre as desigualdades raciais ainda não foi incorporado de forma mais orgânica. Ainda é visto como tema e/ou expressão da questão social. 


\section{ReVIStG PMI PDUtD}

\} SERVIÇO SOCIAL, EDUCAÇÃO E RACISMO - PAULA, A. B. \}

DOI: $10.12957 /$ REP.2020.47223

\section{Considerações finais}

Os espaços educacionais são espaços estratégicos para a manutenção de uma determinada hegemonia, principalmente por sua natureza ideológica. Esses atributos fazem com que todos os níveis educacionais se transformem em arenas de disputas. Inegavelmente, as instituições de ensino reproduzem uma série de conceitos que tanto podem contribuir para manutenção do status quo, como ser um espaço que busca uma transformação social.

Para que contribua nesse processo de transformação, a ação efetiva e balizada do assistente social deve partir da relação indissociável e dialética entre teoria e prática. A leitura do real, ou seja, a compreensão da realidade social é imprescindível para dar viabilidade ao trabalho profissional. Logo, o entendimento fragmentado da dinâmica social brasileira se reflete não apenas na forma como se produz o conhecimento, mas na maneira com que os profissionais atuam em seu cotidiano profissional.

A luta antirracista é um elemento-chave para se pensar a luta de classes. Apenas desse modo pode-se compreender que a expropriação da classe trabalhadora e os níveis crescentes das desigualdades sociais são mediatizadas pela questão étnico-racial, tendo o racismo como um eficaz mecanismo de restrição e seleção do acesso a direitos. Diante disso, as lacunas presentes na produção científica da profissão contribuem para uma análise da realidade que não consegue dar conta da complexidade da dinâmica social brasileira. Além disso, também contribuem para a perpetuação de uma hierarquia cultural e intelectual europeia, que, apesar de contribuir, não responde em sua totalidade às questões apresentadas na realidade social de países colonizados, como o Brasil. 


\section{ReVIStg a d P p putt}

\} SERVIÇO SOCIAL, EDUCAÇÃO E RACISMO - PAULA, A. B. \}

DOI: $10.12957 / R E P .2020 .47223$

\section{Referências}

ABREU, M. M. Serviço Social e a organização da cultura: perfis pedagógicos da prática profissional. São Paulo: Cortez, 2002.

ALMEIDA, N. L. T. Serviço Social e política educacional: um breve balanço dos avanços e desafios dessa relação. In: ENCONTRO DE ASSISTENTES SOCIAIS NA ÁREA DE EDUCAÇÃO, 1. Belo Horizonte, mar. 2003.

ALMEIDA, N. L. T. A educação como direito social e a inserção dos assistentes sociais em estabelecimentos educacionais. In: O Serviço Social e a Política Pública de Educação. Belo Horizonte: Gabinete do Deputado Estadual André Quintão, 2005.

AMARO, S. A questão racial na assistência social: um debate emergente. In: Serviço Social e Sociedade, n. 81, São Paulo: ed. Cortez, 2005.

ARANHA, M. L. A. Filosofia da educação. São Paulo: Ed. Moderna, 1990.

BRASIL. Ministério da Educação. Diretrizes Curriculares para o Ensino das Relações Raciais, Brasília, 2004.

BRASIL. Instituto Brasileiro de Geografia e Estatística. Pesquisa Nacional por Amostra de Domicílios. Brasília, 2015.

FANON, F. Em defesa da revolução africana. Lisboa: Ed. Sá da Costa, 1980.

FERREIRA, N. S. As pesquisas denominadas "estado da arte". Educação e Sociedade, ano XXII, n. 79, ago. 2002.

FREIRE, P. Ação cultural para liberdade e outros escritos. Rio de Janeiro: Paz e Terra, 1981.

GONZALEZ, L. A categoria político-cultural da amefricaneidade. Tempo Brasileiro, Rio de Janeiro, n. 92/93, jan./jun. 1988.

MANDEL, E. O capitalismo tardio. São Paulo: Abril Cultural, 1982.

MARQUES JUNIOR, J. S. Serviço Social e questão racial: um balanço da produção teórica no pós Durban. Monografia de conclusão de curso. Faculdade de Serviço Social, Universidade do Estado do Rio de Janeiro, Rio de Janeiro, 2007. $162 \mathrm{p}$.

MARX, K. O capital. São Paulo: Boitempo, 2012.

MÉSZÁROS, I. A crise estrutural do capital. São Paulo: Boitempo, 2011.

MUNANGA, K. O anti-racismo no Brasil. In: MUNANGA, K. (org.). Estratégias e políticas de combate ao racismo. São Paulo: Editora da Universidade de São Paulo, 1996.

MUNANGA, K. Uma abordagem conceitual das noções de raça, racismo, identidade e etnia. In:SEMINARIO NACIONAL DE RELAÇÕES RACIAIS EM EDUCAÇÃO, 2003. 


\section{ReVIStG PMI PDUtD}

\} SERVIÇO SOCIAL, EDUCAÇÃO E RACISMO - PAULA, A. B. \}

DOI: $10.12957 /$ REP.2020.47223

NETTO, J. P. A construção do projeto ético-político do Serviço Social. In: CAPACITAÇÃO EM SERVIÇO SOCIAL E POLÍTICA SOCIAL, Brasília, CEFESS/ ABEPPS/CEAD/UnB, 1999.

PAULA, A. B. Construindo discursos que constroem sujeitos? Uma discussão sobre a contribuição da Lei n. 10.639/2003 e seu corolário para a afirmação de uma identidade racial positiva no Brasil. Dissertação (Mestrado em Serviço Social) - Programa de Pós-Graduação em Serviço Social, PUC-Rio, Rio de Janeiro, 2011.

PAULA, A. B. Construindo discursos que constroem sujeitos? Um debate sobre a contribuição da Lei n. 10.639/2003 na luta antirracista. Revista O Social em Questão, ano XX, n. 37, jan./abr. 2017.

PINTO, E. A. O Serviço Social e a questão étnico-racial (um estudo de sua relação com usuários negros). São Paulo: Terceira Margem, 2003.

QUIJANO, A. Coloneidade do poder, eurocentrismoe América Latina. In: A colonialidade do saber:eurocentrismo e Ciências Sociais. Perspectivas latinoamericanas. Buenos Aires: CLACSO, 2005.

RIBEIRO, M. As abordagens étnico-raciais no Serviço Social. In: Serviço Social e Sociedade n.79, São Paulo: ed. Cortez, 2004.

ROCHA, R. F. A Questão étnico-racial no processo de formação em Serviço Social. In: Serviço Social e Sociedade, n. 99. São Paulo: Cortez, 2009. .

ROCHA, R. F. A incorporação da temática étnico-racial no processo de formação em serviço social: avanços e desafios. Tese (Doutorado) - Programa de Pós-Graduação em Serviço Social. Escola de Serviço Social da UFRJ. 2014. Mime.

SILVA, A. P. P. da. O contrário de casa grande não é senzala. É quilombo! A categoria práxis negra no pensamento social de Clóvis Moura. 2017. 274f. Tese (Doutorado em Serviço Social) - Escola de Serviço Social, Universidade Federal do Rio de Janeiro, Rio de Janeiro, 2017.

SILVA FILHO, J. B. O Serviço Social e a questão do negro na sociedade brasileira. Rio de Janeiro: Marques Saraiva, 2006.

TEIXEIRA, J. B.; BRAZ, M. O projeto ético-político do Serviço Social. In: CFESS-ABEPSS. Serviço Social: direitos sociais e competências profissionais. Brasília: CFESS-ABEPSS, 2009.

DOI: $10.12957 /$ rep.2020.47223

Recebido em 21 de julho de 2019. Aprovado para publicação em 31 de outubro de 2019.

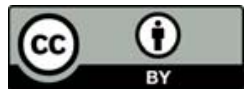

A Revista Em Pauta: Teoria Social e Realidade Contemporânea está licenciada com uma Licença Creative Commons Atribuição 4.0 Internacional. 